\title{
Correction to: Inflammation as a Mechanism of Bipolar Disorder Neuroprogression
}

Tatiana Barichello, Vijayasree Vayalanellore Giridharan, Gursimrat Bhatti, Pavani Sayana, Tejaswini Doifode, Danielle Macedo, and Joao Quevedo

\section{Correction to:}

\section{Chapter "Inflammation as a Mechanism of Bipolar} Disorder Neuroprogression"' in: T. Barichello et al., Curr Topics Behav Neurosci, https://doi.org/10.1007/7854_2020_173

The original version of this chapter is updated with the below mentioned updates as per the author's request:

1. The author name "Vijayasree V. Giridharan" is now updated with full name as Vijayasree Vayalanellore Giridharan, so that in the PubMed the name appears as Giridharan VV.

2. Figure 1 is now included in the content in Sect. 3.1 Mechanisms of inflammation and their contribution to BD neuroprogression.

The original article has been updated. 